\title{
Improving of Cryopreservation Quality of Spermatogonial Stem Cells after Freezing-Thawing by Melatonin
}

\author{
Tahoora nazeri Tile Noei, Farzane Farokhi* and Ali Ahmadi \\ Department of Biological Sciences and Technologies, Islamic Azad University of Sari Branch, Iran
}

\begin{abstract}
Cryopreservation of spermatogonial stem cells (SSCs) is an advantageous method to restore fertility in young boys' cancer survivors. Recently, for reduction of SSCs cryoinjering various antioxidants have been used. The purpose of this study was to evaluate antioxidant effects of melatonin in frozen-thawed SSCs. Spermatogonial stem cells were isolated from testes of neonate mice (3-6 days old) and their purities were measured by flow cytometry with GFR 1 1. After culturing, the cells were frozen in two groups 1control and 2- melatonin $(100 \mu \mathrm{M})$ for one month. Finally, the cell viability, colonization rate, intracellular ROS were evaluated after freezing thawing. Melatonin increased the viability, colonization of SSCs, and decreased intracellular ROS. The results of this study show that melatonin with antioxidant effects as a good option can be used for freezing and long-term storage of cells and infertility treatment in the clinic.
\end{abstract}

KEYWORDS: Cryopreservation; Melatonin; Spermatogonial stem cells

ABBREVIATIONS: SD: Standard Deviation; SSCs: Spermatogonial Stem Cells; GDNF: Glial Cell-Derived Neurotrophic Factor; PLZF: Promyelocytic Leukemia Zinc Finger; GFR $\alpha 1$ : GDNF family receptor $\alpha 1$; LIF: Leukemia Inhibitory Factor

\section{INTRODUCTION}

Recent success in cancer treatment has increased in prepubertal boys that have cancer and receive high doses of chemotherapy and radiotherapy. It has been reported that $35 \%$ of young boy's cancer survivors become infertile in adulthood because spermatogonial stem cells are very sensitive to the toxic effects of cancer treatment $[1,2]$. In fact, trying to return fertility in these children is one of the most important subjects in clinical and research area. The cryopreservation of SSCs and finally transplantation of SSCs after recovery can initiate spermatogenesis and fertility in these patients [3-5].

Spermatogenesis process with the aim of correct transfer of genetic factors to the next generation depends on the spermatogonial stem cells [6,7]. SSCs as undifferentiated cells have ability of selfrenewal, differentiation and transferring genetic information to the next generation and are therefore considered unique cells among human stem cells [8-10].

Cryopreservation as an effective method for infertility preservation is associated with biochemical changes of the cell plasma membrane, increased reactive oxygen species, DNA fragmentation, decreased cell activity and finally reduced fertility of SSCs [11,12]. So far, different antioxidants have been used to reduce the injuries following cryopreservation [13-15]. Despite the introduction of antioxidant agents and useful effects of them, the use of a suitable factor to minimize the freezing complications is still debated.

Melatonin as a hormone has antioxidant, anti-inflammatory, and anti-apoptotic properties in different types of stem cells $[16,17]$. Several reports have emphasized that melatonin as an effective antioxidant has a key role in increasing antioxidant enzymes and
Quick Response Code:

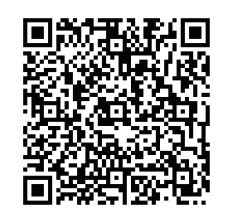

Address for correspondence: Farzane Farokhi, Department of Biological Sciences and Technologies, Islamic Azad University of Sari Branch, Iran

Received: November 2, $2021 \quad$ Published: November 15, 2021

How to cite this article: Tahoora TN, Farzane F, Ali A. Improving of Cryopreservation Quality of Spermatogonial Stem Cells after Freezing-Thawing by Melatonin. 2021- 3(6) OAJBS.ID.000348. DOI: $10.38125 / \mathrm{OAJBS} .000348$ 
scavenging free radicals. In fact, melatonin with this characteristic can protect SSCs against oxidative stress [18,19]. Moreover, melatonin, with its antioxidant properties has an important role in regulating self-renewal and differentiation of stem cells. There is also evidence of the role of melatonin as an appropriate cryoprotectant in male reproductive system [20-22]. Considering the above and the lack of knowledge regarding suitable factors for long-term preservation of SSCs, this study aimed at assessing the antiapoptotic and antioxidant effects of melatonin in improving of Cryopreservation quality of Spermatogonial Stem Cells.

\section{METHODS AND MATERIALS}

\section{Isolation and Enrichment of SSCs}

In this section, male BALB/c mice (3-6 days old) were used to isolate of SSCs. The protocol of Kanatsu-Shinohara with some modification was used for isolating SSCs. Briefly, under sterile conditions the removed testes were rapidly washed in PBS supplemented with $1 \%$ penicillin/streptomycin (Sigma-Aldrich) and then mechanical digestion was performed carefully. The minced samples were put into digestion medium containing $5 \mu \mathrm{g} /$ $\mathrm{mL}$ DNase (Sigma-Aldrich.USA), $1 \mathrm{mg} / \mathrm{mL}$ collagenase type IV (Gibco,CA), and $1 \mathrm{mg} / \mathrm{mL}$ hyaluronidase (Sigma-Aldrich. USA) and incubated at $37{ }^{\circ} \mathrm{C}$ for $20 \mathrm{~min}$ with $5 \% \mathrm{CO}_{2}$ and then pipetted gently every 5 minutes. Finally, Centrifugation was done at $1,500 \mathrm{~g}$ for $5 \mathrm{~min}$. The second stage of enzymatic digestion was performed using the same method and digestion medium. SSCs obtained from enzymatic digestion were purified using the plating differential technique. In this technique, the cells were transferred to culture dishes coated with Lectin for $2 \mathrm{~h}$ at $37^{\circ} \mathrm{C}$. After $2 \mathrm{~h}$, somatic cells attach to the bottom of the dish and the supernatant containing the purified SSCs is collected. Flow cytometry using GFR $\alpha 1$ marker was used to determine the purity of the collected SSCs. First, 105 cells were incubated in $100 \mu \mathrm{l} \mathrm{PBS} / \mathrm{FBS}$ and $10 \mu \mathrm{l}$ primary antibody (1:100) at $4{ }^{\circ} \mathrm{C}$ for 1 hour. After washing twice with PBS, the cells were incubated in $100 \mu \mathrm{l}$ PBS/FBS and $10 \mu$ l secondary antibody at $4{ }^{\circ} \mathrm{C}$ for 1 hour. FITC goat anti-rabbit IgG H\&L (ab6717, Abcam, UK) was used as the secondary antibody for GFR $\alpha 1$. The control cells were not treated with any antibodies. Finally, the cells were kept in a dark room on ice and the purity percentage was determined by flow cytometry.

\section{Culture of SSCs}

Purified cells $(2 \times 105$ cell $/ \mathrm{cm} 2)$ were seeded in culture dishes and culture medium containing Dulbecco's modified Eagle's medium (DMEM) supplemented with 10\% fetal bovine serum (FBS, Life Technologies), 10ng/Ml Leukemia Inhibitory Factor (LIF; Sigma, Haverhill), 10ng/mL basic fibroblast growth factor (Peprotech, Rocky Hill, NJ), 10ng/mL glial cell line-derived neurotrophic factor (GDNF; Sigma- Aldrich), 100U/mL penicillin (Sigma-Aldrich, Darmstadt), and $100 \mu \mathrm{g} / \mathrm{mL}$ streptomycin (Sigma, Germany) was added to cells. Finally, culture dishes were transferred in a humidified $5 \%$ CO incubator at $37{ }^{\circ} \mathrm{C}$ and the fresh medium was replaced every 2-3 days.

\section{Dosimetry of Melatonin}

The methyl thiazol tetrazolium assay (MTT; Sigma-Aldrich) was applied to define the optimum concentration of melatonin. In this technique, cell viability was evaluated in control and treatment groups with 50,100 , and $150 \mu \mathrm{m} / \mathrm{ml}$ melatonin after the freezingthawing process. First, $400 \mu \mathrm{l}$ DMEM and $40 \mu \mathrm{l}$ MTT were added to SSCs, and the mixture was incubated at $37{ }^{\circ} \mathrm{C}$ for 4 hours. Then,
MTT solution was replaced with $400 \mathrm{~mL}$ dimethyl sulfoxide freezing solution (DMSO; Sigma). The optical density was measured at 540nm using an Elisa Reader (BioTek Instruments).

\section{Freezing-Thawing Process}

Freezing of SSCs was done according to a protocol described by Izadyar et al. After cell harvesting, the cells $(0.5 \mathrm{~mL})$ was transferred to a $1.8 \mathrm{~mL}$ freezing vial (Cryovial, Nunc, Denmark) and basal freezing medium, including 10\% DMSO and 10\% FBS was slowly added to the cells. After complete blending, the cryovials were kept to a $-80{ }^{\circ} \mathrm{C}$ freezer overnight. Then, the frozen vials were dunked in liquid nitrogen for 1 month. The treated group was frozen in the basic freezing medium with $100 \mu \mathrm{m} / \mathrm{ml}$ melatonin (SigmaAldrich). For thawing, the cryovials were put at room temperature for 30 seconds and then quickly transferred in a $37{ }^{\circ} \mathrm{C}$ water bath for 2 minutes. The thawed cells were transferred to a falcon tube containing DMEM and 10\% FBS. Finally, cell centrifugation was done at $1500 \mathrm{~g}$ for 5 minutes. After removing the supernatant solution, the cell pellet was used to perform the further techniques.

\section{Assessment of Cell Viability}

To determine the melatonin effect on cell viability, MTT assay was done on cultured cells after the freezing-thawing process. First, SSCs were seeded in a 96-well plate and $400 \mu \mathrm{L}$ DMEM with $40 \mu \mathrm{l} \mathrm{MTT}$ were added to SSCs. Then plate was incubated at $37{ }^{\circ} \mathrm{C}$ for 4 hours. After discarding of MTT solution, $400 \mathrm{~mL}$ DMSO was replaced. The optical density was measured at 540nm using an Elisa Reader (BioTek Instruments).

\section{Colony Assay}

To Assessment the melatonin effect on SSCs colonization, SSCs (2 x 105 cell/cm2) were seeded in petri dishes. Cells were cultivated in a DMEM containing 10\% FBS, 100U/mL penicillin, $100 \mathrm{mg} / \mathrm{mL}$ streptomycin, $10 \mathrm{ng} / \mathrm{mL}$ LIF, and $10 \mathrm{mg} / \mathrm{mL}$ GDNF in $5 \%$ $\mathrm{CO} 2$ at $37^{\circ} \mathrm{C}$ for 1 week after the freezing-thawing process. The SSC colonies were observed and captured using an Invert microscope. Then, the number and diameter of the colonies were analyzed using the Image J software.

\section{Assessment of Intracellular ROS}

The intracellular ROS was measured using 2', 7'dichlorofluorescein diacetate (DCFH-DA; Sigma-Aldrich) as a fluorescent oxidative probe. First, the cells were incubated with $10 \mu \mathrm{l}$ of $2^{\prime}, 7^{\prime}$-dichlorofluorescin diacetates at $37^{\circ} \mathrm{C}$ for 25 minutes. Next, the fluorescence intensity of DCFH-DA was assessed between 500 and 530nm wavelengths using a BD FACScan flow cytometer (Becton Dickinson, San Jose, CA).

\section{Statistical Analysis}

The results were processed using the GraphPad Prism 7.0 (GraphPad Software, Inc., La Jolla, CA). One-way ANOVA and Tukey post-hoc test was used for the statistical analysis of the results. $P$ values less than 0.05 were considered statistically significant $(P \leq 0.05)$. The data were presented as mean \pm standard

\section{RESULTS}

\section{Evaluation of the Purification of SSCs}

Determining the purity of SSCs $(2 \times 105$ cell/cm2) were done using flow cytometry with undifferentiated marker GFR 1 after enzymatic digestion and differential plating. The results analysis of 

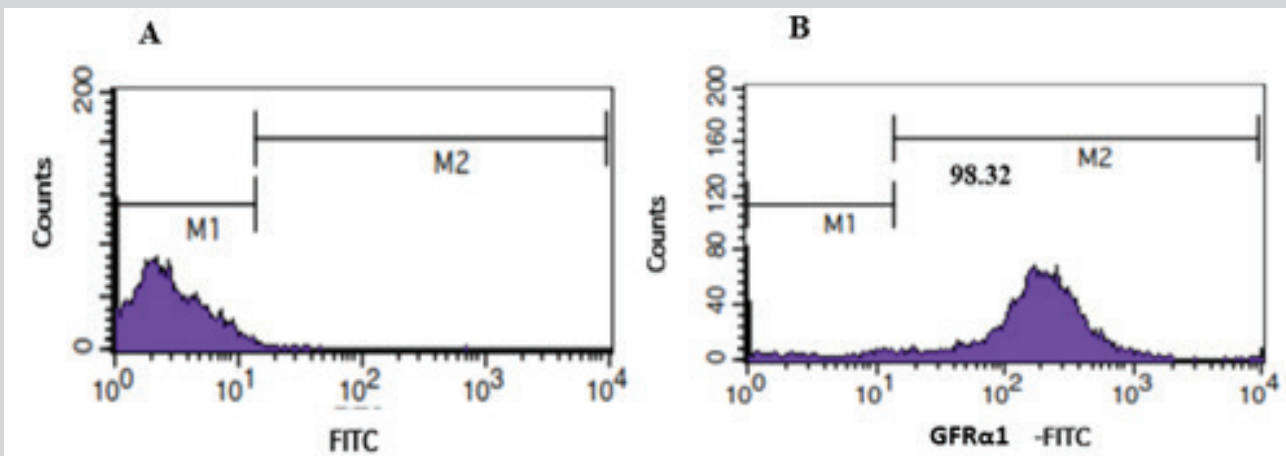

Figure 1: Results of flow cytometry indicating the purity percentage of SSCs with GFRal marker. M1: Marker Negative Cells; M2: Marker Positive Cells; A: Control; B: GFRa 1 positive.

\section{SSC Morphology and Confirmation of Colonies}

The purified SSCs were cultured to reach optimal confluence before freezing process. Confirmation of SSC colonies were performed by Alkaline phosphatase staining. The red color of the colonies demonstrated the stem cell alkaline phosphatase activity in the colonies (Figure 2).

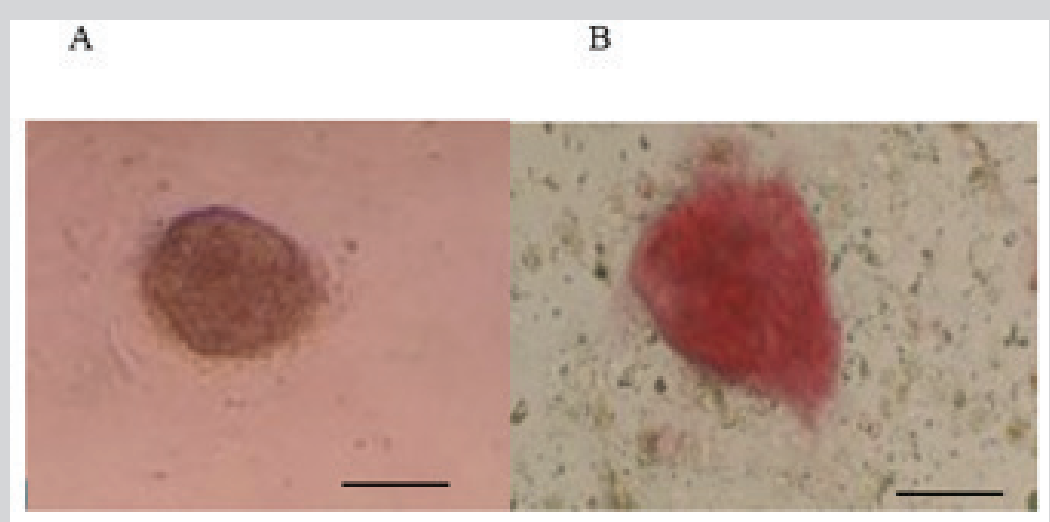

Figure 2: Assessment of SSCs colonization.

A: Colony of SSCs. B: Alkaline phosphatase positive colony Scale bars $=100 \mu \mathrm{m}$

\section{Dosimetry of Melatonin}

The MTT assay was applied to detect the optimum concentration of melatonin one month after cryopreservation. The results demonstrated that $100 \mu \mathrm{M}$ melatonin significantly increased the cell viability $(95.83 \pm 0.88)$ compared to other groups. According to these results, $100 \mu \mathrm{M}$ of melatonin was selected as the optimum concentrations in this study (Figure 3).

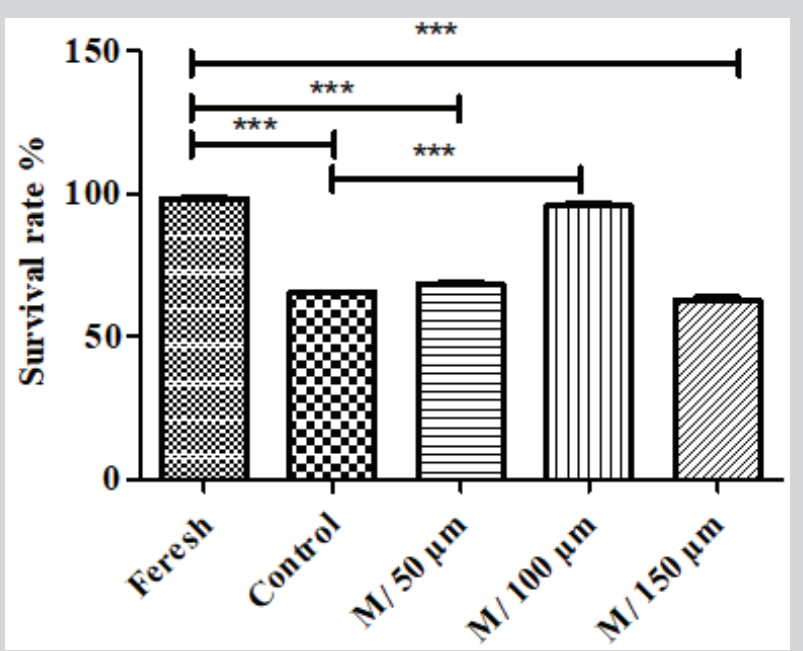

Figure 3: Determining the optimum concentration of melatonin by MTT assay. According to these results, $100 \mathrm{nM}$ of melatonin was selected as the optimum concentrations. The experiment was performed in triplicate and repeated three times. The results are reported as mean $\pm \mathrm{SE},{ }^{* * *} p<0.001$. 


\section{Effect of Melatonin on Viability of SSCs}

After freezing- thawing process, the viability of SSCs were evaluated by MTT technique. The results of MTT assay displayed that the freezing-thawing process notably decreased the viability of SSCs in the control group $(65.17 \pm 0.31)$ compared to the fresh group. Also, the viability of treated SSCs with melatonin was significantly higher $(96.77 \pm 0.18)$ compared to the control group (Figure 4).

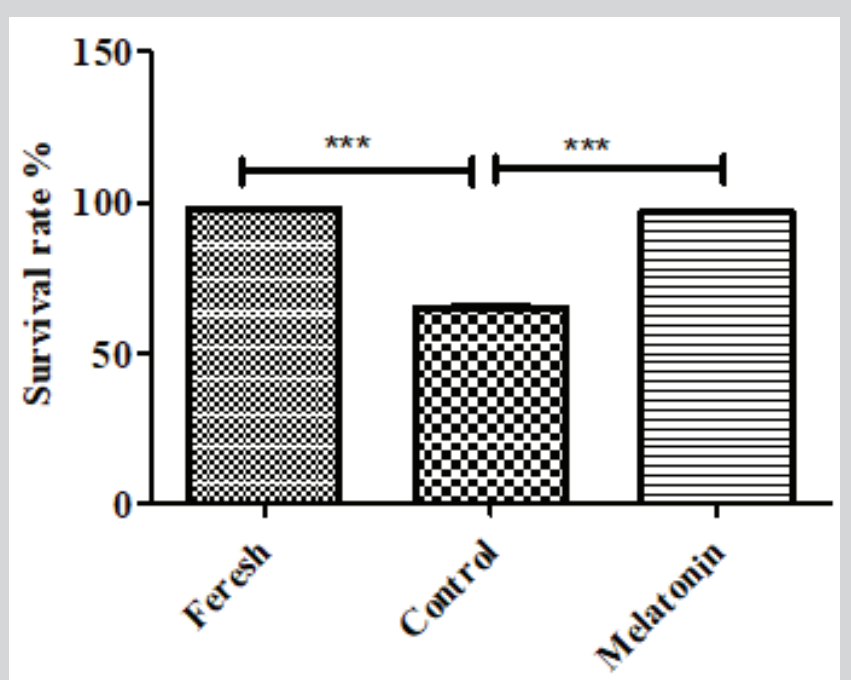

Figure 4: Analysis of the cell viability after the thawing process by using the MTT. Viability percentage in melatonin group was significantly more than other groups and close to the fresh group. The experiment was performed in triplicate and repeated three times (there are $2 \times 105 \mathrm{cell} / \mathrm{cm} 2$ of SSCs in each group). The results are reported as mean $\pm S E, * * * p<0.001$.

\section{Effect of Melatonin on Intracellular ROS}

The level of ROS production was measured in three groups of SSCs including fresh, control and cryopreservation with melatonin. This experiment data analysis indicated that ROS production was notably higher in the control group $(48.50 \pm 0.28)$ compared with the other groups. Whereas ROS production decreased significantly in the cryopreservation group with melatonin $(24.83 \pm 0.12)$ compared with the control group (Figure 5).
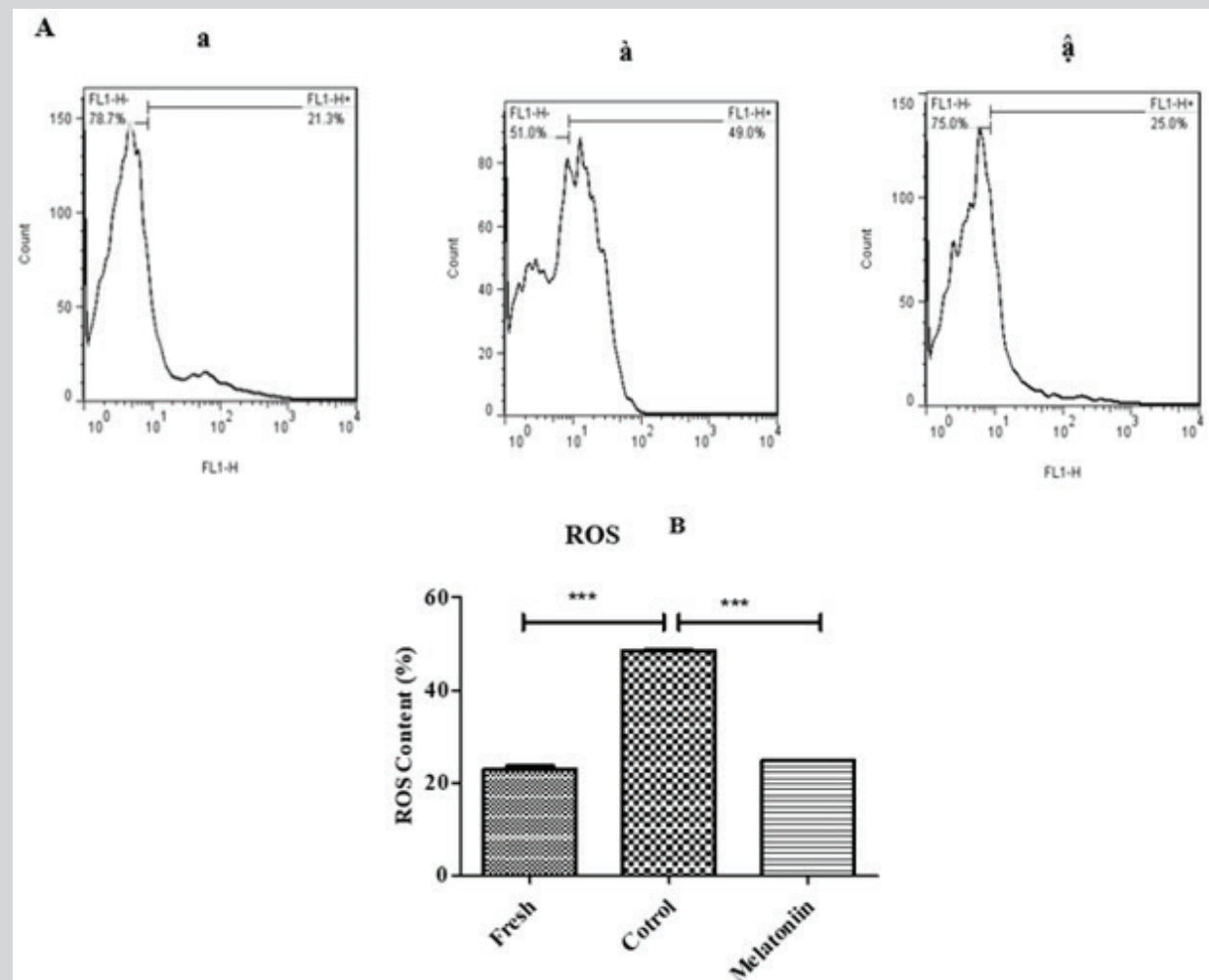

Figure 5: A- Measurement of intracellular ROS after the thawing process by using DCFH-DA staining in different experimental groups (a): fresh, (à): control, (ậ): melatonin. B- Analysis of intracellular ROS production. Melatonin significantly decreased ROS level. The experiment was performed in triplicate and repeated three times (there are $2 \times 105$ cell/cm2 of SSCs in each group). The results are reported as mean $\pm S E, * * * p<0.001$. 


\section{Colony Assay}

Assessment of the melatonin effect on colonization of frozenthawed SSCs were done by an inverted microscope and Image J software one week after culturing the thawed SSCs (Figure 6).
Data analysis showed that melatonin could effectively increase $(195.9 \pm 6.06)$ the diameter of SSC colonies in comparison with the control group. The number of colonies was significantly larger in SSCs treated with melatonin $(4.66 \pm 0.33)$ compared to the control group (Figure 6).
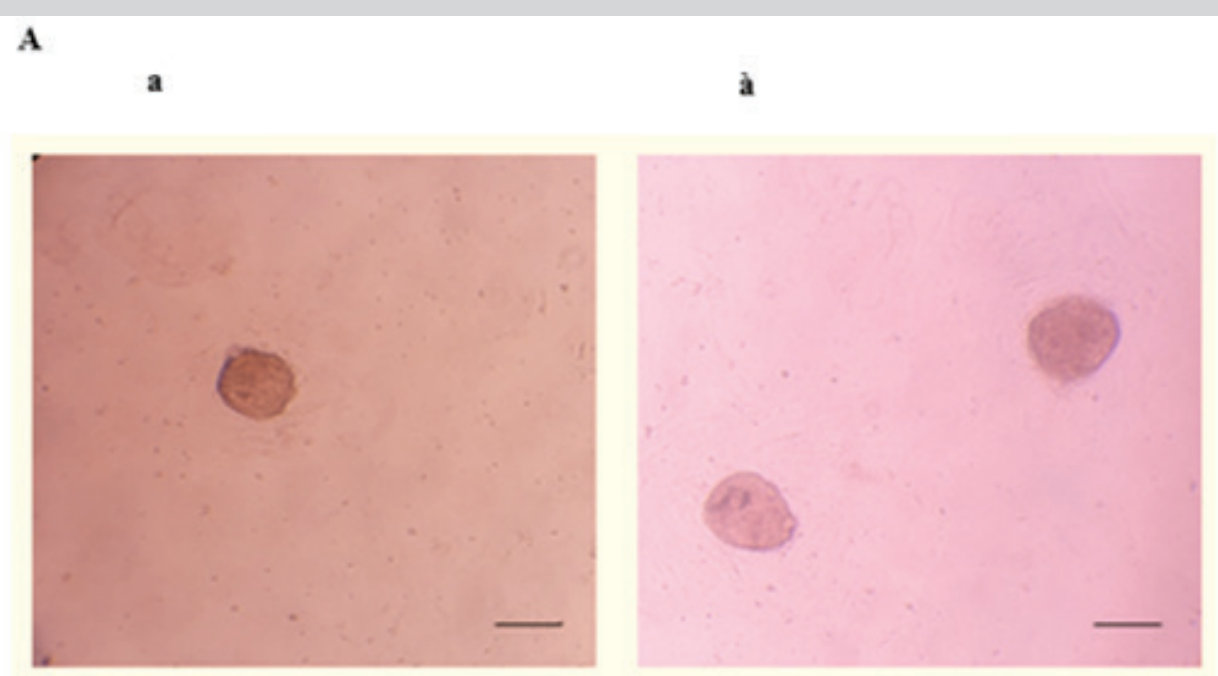

B

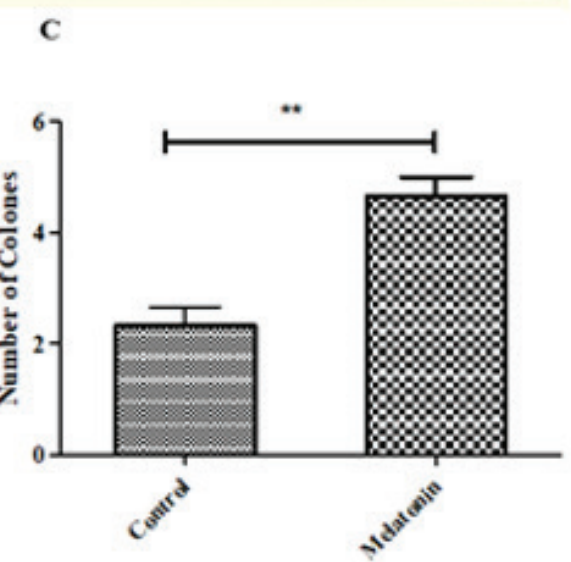

Figure 6: A-Microscopic morphology of SSCs cultured 1 week after the freezing-thawing process. a: control group.

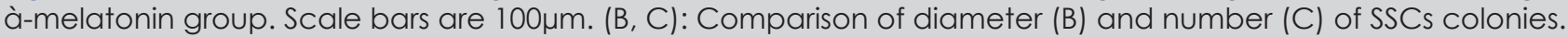
The experiment was performed in triplicate and repeated three times (there are $2 \times 105 \mathrm{cell} / \mathrm{cm} 2$ of SSCs in each group). The results are reported as mean \pm SE. ${ }^{* * * *} p \leq 0.0001$ and ${ }^{* *} p \leq 0.01$.

\section{DISCUSSION}

Infertility occurs in almost one-third of the young boy's cancer survivors due to toxic effects of chemotherapy and radiotherapy drugs [15]. Freezing and long-term preservation of SSCs as an effective method for restoration of fertility is one of the most important subjects in clinical and research field [23,24]. Previous studies showed that normal function of SSCs decreases after the freeze-thaw process due to cryoinjuries. Therefore, it is necessary to add cryoprotectants to the freeze medium of SSCs $[25,26]$. In this study, melatonin as a cryoprotectant was added in the freeze medium to reduce injuries of cells after the freeze-thaw process.

The results of this study showed that cryopreservation of SSCs with $100 \mu \mathrm{m}$ melatonin improved cell viability compared to the control group. As reported by other studies, melatonin as a cryoprotectant also increased cell viability after thawing process $[27,28]$. According to evidence Cryoprotectants that are added to the freezing medium are divided to intracellular and extracellular cryoprotectants. The intracellular cryoprotectants have a low molecular weight and the ability to penetrate the cell membrane. They protect cells against cryoinjuries through these properties. The extracellular cryoprotectants with formation a sheath around the cells prevent cell dehydration during freezing. In fact, cryoprotectants act through two different mechanisms to diminish cryoinjuries [29]. It seems that melatonin enhances the viability of SSCs through formation of a sheath around cells to prevent cell water loss during cryopreservation.

Freezing process increases the intracellular ROS production. An increase in the intracellular ROS led to cell injuries such as lipid peroxidation, protein oxidation and DNA fragmentation. For this reason, in this study melatonin was added to the freeze medium to reduce ROS production. The results showed a marked reduction in intracellular ROS production in melatonin treated SSCs compared to the control group. Many researchers found that melatonin, as a potent antioxidant, could reduce oxidative stress and protect the sperm against cryoinjury through scavenging the produced ROS [30]. It seems that melatonin can eliminate ROS probably through neutralizing toxic free radicals. 
In general, we believe that melatonin, as a cryoprotectant, protects SSCs from cryoinjuries. Although the exact mechanism is not clear, two general categories of explanations have been proposed: 1- melatonin may cause changes in the physical condition of the freeze medium and may form a sheath around cells to minimize dehydration, 2- Melatonin may protect cells through a mechanism independent of receptors that facilitates the elimination of free radicals.

According to the results of this study, melatonin may be a suitable candidate for freezing, long-term cell preservation, and infertility treatment in the clinical setting considering its antioxidant and anti-apoptotic properties as well its effects on increased colonization and cell viability of SSCs.

\section{CONCLUSION}

Based on the results, it can be deduced that melatonin with antioxidant and anti-apoptosis effects can be used as a useful antioxidant for freezing and long-term storage of cells in the clinic.

\section{AVAILABILITY OF DATA AND MATERIALS}

All data generated or analyzed during this study are included in this published article.

\section{ACKNOWLEDGMENT}

The present research has been performed in department of anatomy - Tehran University of Medical Sciences, Tehran, Iran.

\section{AUTHOR CONTRIBUTIONS}

T. N Designed experiment and Performed study. F.F Performed analyses, edited article, and supervised the research.

\section{REFERENCES}

1. Lotti F, Maggi M (2018) Sexual dysfunction and male infertility. Nature Reviews Urology 15(5): 287-307.

2. Picton HM, Christine W, Richard AA, Ellen G, Kirsi J, et al. (2015) A European perspective on testicular tissue cryopreservation for fertility preservation in prepubertal and adolescent boys. Human Reproduction 30(11): 2463-2475.

3. Keefe DT, Anne-Sophie B, Mandy R, Nagam Y, Rose C, et al. (2021) Spermatogenesis in pre-pubertal boys with Leydig cell neoplasms suggests paracrine stimulation by testosterone. J Pediatr Urol 17(1): 48.e1-48.e6.

4. Jurewicz M, Joel H, Sandeep M, Bruce RG (2018) Fertility preservation in pubertal and pre-pubertal boys with cancer. Pediatr Endocrinol Rev 15(3): 234-243.

5. Shetty G, Jennifer MM, Truong NL, Thien TP, Jie Z, et al. (2021) Postpubertal spermatogonial stem cell transplantation restores functional sperm production in rhesus monkeys irradiated before and after puberty. Andrology 9(5): 1603-1616.

6. Chen SR, Liu YX (2015) Regulation of spermatogonial stem cell selfrenewal and spermatocyte meiosis by Sertoli cell signaling. Reproduction 149(4): R159-R167.

7. Khanehzad M, Farid A, Gholamreza H, Seyed MN, Azim H (2020) Determination of the excitatory effects of microRNA-30 in the selfrenewal and differentiation process of neonatal mouse spermatogonial stem cells. Galen Medical Journal 9: 1829.

8. de Michele F, Vermeulen M, Wyns C (2017) Fertility restoration with spermatogonial stem cells. Curr Opin Endocrinol Diabetes Obes 24(6): 424-431.

9. Naeemi S, Akram E, Ramezan K, Homan SA, Abdol MK (2021) Differentiation and proliferation of spermatogonial stem cells using a three-dimensional decellularized testicular scaffold: A new method to study the testicular microenvironment in vitro. Int Urol Nephrol 53(8): 1543-1550.

10. Khanehzad M, Roya A, Marzieh H, Mohammad HM, Seyed MN (2021) FSH regulates RA signaling to commit spermatogonia into differentiation pathway and meiosis. Reprod Biol Endocrinol 19(1): 4.

11. Sinha N, Whelan EC, Brinster RL (2019) Isolation, cryopreservation and transplantation of spermatogonial stem cells. Methods Mol Biol 2005: 205-220.

12. Marinović Z, Jelena L, Qian L, Yoshiko I, Béla U, et al. (2021) Cryopreservation and transplantation of spermatogonial stem cells. Methods Mol Biol 2218: 37-47.

13. Aliakbari F, Mohammadhossein H, Mohammad AH, Jalil H (2019) Increasing of post-freezing quality of Spermatogonial Stem Cells after pretreatment by vitamin E. Men's Health Journal 3(1): e1.

14. Amidi F, Zahra R, Zahra K, Kajal K, Ali T, et al. (2019) Antioxidant effects of quercetin in freeze-thawing process of mouse spermatogonial stem cells. Asian Pacific Journal of Reproduction 8(1): 7.

15. Khanlari P, Maryam K, Zahra K, Aligholi S, Shogoofa B, et al. (2021) Effect of miR-30a-5p on apoptosis, colonization, and oxidative stress variables in frozen-thawed neonatal mice spermatogonial stem cells. Biopreserv Biobank 19(4): 258-268.

16. Zhang X, Qin X, Rui W, Hongfei S, Jiaqi M, et al. (2019) Melatonin protects spermatogonia from the stress of chemotherapy and oxidation via eliminating reactive oxidative species. Free Radic Biol Med 137: 74-86.

17. Feng TY, Qian L, Fa R, Hua-Ming X, Dong L, et al. (2020) Melatonin protects goat spermatogonial stem cells against oxidative damage during cryopreservation by improving antioxidant capacity and inhibiting mitochondrial apoptosis pathway. Oxid Med Cell Longev 2020: 5954635.

18. Li B, Xin H, Mengru Z, Bowen N, Chongyang W, et al. (2018) Melatonin ameliorates busulfan-induced spermatogonial stem cell oxidative apoptosis in mouse testes. Antioxid Redox Signal 28(5): 385-400.

19. Navid S, Abbasi M, Hoshino Y (2017) The effects of melatonin on colonization of neonate spermatogonial mouse stem cells in a threedimensional soft agar culture system. Stem Cell Res Ther 8(1): 233.

20. Chen XJ, Zhang Y, Jia GX, Meng QG, Bunch TD, et al. (2016) Effect of melatonin supplementation on cryopreserved sperm quality in mouse. Cryo Letters 37(2): 115-122.

21. Najafi A, Emmanuel A, Abazar Y, Ensieh S, Saideh M, et al. (2018) Melatonin affects membrane integrity, intracellular reactive oxygen species, caspase 3 activity and AKT phosphorylation in frozen thawed human sperm. Cell Tissue Res 372(1): 149-159.

22. Sun TC, Hui YL, Xiao-Yu L, KunY, Shou L, et al. (2020) Protective effects of melatonin on male fertility preservation and reproductive system. Cryobiology 95: 1-8.

23. Xie Y, Haicheng C, Daosheng L, Xing Y, Jiahui Y, et al. (2020) Inhibiting necroptosis of spermatogonial stem cell as a novel strategy for male fertility preservation. Stem Cells Dev 29(8): 475-487.

24. Boroujeni MB, Fatemeh P, Afshin P, Nasim BB, Seyyed AY, et al. (2019) Effect of selenium on freezing-thawing damage of mice spermatogonial stem cell: a model to preserve fertility in childhood cancers. Stem Cell Investig 6: 36 .

25. Ha SJ, Byung GK, Yong AL, Yong HK, Bang JK, et al. (2016) Effect of antioxidants and apoptosis inhibitors on cryopreservation of murine germ cells enriched for spermatogonial stem cells. PLoS One 11(8): e0161372.

26. Kazemzadeh S, Tayebeh R, Bagher MZ, Mehrnoush M, Maryam K, et al. (2021) Effect of a freezing medium containing melatonin on markers of pre-meiotic and post-meiotic Spermatogonial Stem Cells (SSCs) after transplantation in an azoospermia mouse model due to testicular torsion. Reprod Sci 28(5): 1508-1522.

27. Sun X, Zhanhui O, Ruochan C, Xiaohua N, Chen D, et al. (2016) Activation of the p62-Keap1-NRF2 pathway protects against ferroptosis in hepatocellular carcinoma cells. Hepatology 63(1): 173-184. 
28. Chaithra SA, Shailesh DI, Vikas DD, Anagha SN, Simin VB, et al. (2020) Effect of melatonin on bovine sperm characteristics and ultrastructure changes following cryopreservation. Vet Med Sci 6(2): 177-186.

29. Jung H, Kim N, Yoon M (2016) Reproductive stage-dependent effects of additional cryoprotectant agents for the cryopreservation of stallion germ cells. Anim Reprod Sci 173: 24-28.
30. Karimfar MH, Niazvand F, Haghani K, Ghafourian S, Shirazi R, et al. (2015) The protective effects of melatonin against cryopreservation-induced oxidative stress in human sperm. Int J Immunopathol Pharmacol 28(1): 69-76. 